\title{
The impact of COVID-19 on destination visit intention and local food consumption
}

Article

Accepted Version

Dedeoğlu, B. B. ORCID: https://orcid.org/0000-0002-07223392, Mariani, M. ORCID: https://orcid.org/0000-0002-79162576, Shi, F. ORCID: https://orcid.org/0000-0001-8176-4712 and Okumus, B. ORCID: https://orcid.org/0000-0003-23953384 (2022) The impact of COVID-19 on destination visit intention and local food consumption. British Food Journal, 124 (2). pp. 634-653. ISSN 0007-070X doi:

https://doi.org/10.1108/BFJ-04-2021-0421 Available at https://centaur.reading.ac.uk/103353/

It is advisable to refer to the publisher's version if you intend to cite from the work. See Guidance on citing.

Published version at: http://dx.doi.org/10.1108/BFJ-04-2021-0421

To link to this article DOI: http://dx.doi.org/10.1108/BFJ-04-2021-0421

Publisher: Emerald

All outputs in CentAUR are protected by Intellectual Property Rights law, including copyright law. Copyright and IPR is retained by the creators or other copyright holders. Terms and conditions for use of this material are defined in the End User Agreement. 


\section{CentAUR}

Central Archive at the University of Reading

Reading's research outputs online 


\section{The impact of COVID-19 on destination visit intention and local food consumption}

\section{Purpose:}

This paper aims to investigate the relationships between motivation and intention to consume local food and between intention to consume local food and intention to visit the destination of that food's origin while examining the moderating effect of risk perception associated with COVID-19.

\section{Design/methodology/approach:}

Data were collected from two samples of potential Chinese tourists in the contexts of Italian and Thai food. Data obtained from 264 Chinese respondents for Italian food and 277 Chinese respondents for Thai food were analyzed. Partial least squares structural equation modeling was utilized to test the research model.

\section{Findings:}

The results indicate that, while motivational factors such as cultural experience, novelty, and sensory appeal influence potential Chinese tourists' intention to consume Italian food, motivational factors such as cultural experience, health concern, novelty, and sensory appeal influence tourists' intention to consume Thai food. We found that intention to consume local food positively influences tourists' intention to visit both destinations (Italy and Thailand). Moreover, tourists' risk perceptions of COVID-19 negatively moderate the effect of cultural experience and novelty on the intention to consume Italian food. Regarding the intention to consume Thai food, we found that tourists' risk perceptions have a diminishing effect on all motivational factors.

\section{Originality/value:}

This pioneering study examines the role of COVID-19-related risk perception on the relationships among motivation of local food consumption, intention of local food consumption, and destination visit intention in the context of two destination countries. It reveals cross-country differences of the negative effect pertaining to the risk perceptions of COVID-19, which has important implications for international destination marketing.

Keywords: COVID-19, local food consumption, destination visit intention, risk perception.

\section{Introduction}

Competition among tourism destinations to attract tourists has been growing over the last decade (Dedeoğlu et al., 2020; Mariani et al., 2021; Soltani et al., 2021). Given this, destination 
management organizations (DMOs) are increasingly investing in ways of predicting tourists' expectations to enhance their visiting intention (Back et al., 2020; Dedeoğlu et al., 2019; Mariani et al., 2014) by focusing on unique culinary products. According to a report published by Travel Weekly (2018), 64\% of all destination selection decisions are influenced by the variety and attractiveness of local foods. Therefore, local and ethnic food can offer cultural, authentic, and unique experiences to a majority of tourists (Okumus et al., 2007; Richards, 2021). It is now clear that local foods are an important factor in destination selection (Okumus and Cetin, 2018). Therefore, factors driving tourists to consume local food need to be identified and examined clearly.

Motivation is one of the most important predictors shaping an individual's intention toward an object. Consumer motivation refers to the processes underlying buying behavior and explains the factors driving consumers to purchase or consume a product (Solomon et al., 2013). In this sense, local food consumption motivation is expected to influence the intention to consume local food, as affirmed by previous studies (Mak et al., 2017).

However, the outbreak of the COVID-19 epidemic in December 2019 led to major changes in consumption habits and behaviors (Wang et al., 2020). To deal with the pandemic, most countries have implemented several restrictions and lockdowns (Muhammad et al., 2020) that have affected consumers' habits (Lee, 2020). Although vaccines have been rolled out over the last few months, definitive conclusions about the effectiveness of these vaccines are still unclear (Su et al., 2021). In addition, even if these vaccines are effective, the pandemic might persist for years (BusinessToday, 2020). With COVID-19, there are some concerns about whether people can live and comply with social distancing restrictions and lockdowns for an extended period considering the social nature of human beings (Rozenkrantz et al., 2020). Many countries are facing protests against COVID-19 restrictions (Dartford, 2021). Such protests indicate that individuals are ready to go back to daily activities and participate in travel and tourism activities to meet their socialization needs. Although it is still early to indicate the travel-related risk perceptions of travelers, travel risks can be lowered with vaccinations, masks, and social distancing measures - all of which might encourage individuals' willingness to travel and participate in tourism activities. However, this situation raises an important question, which also constitutes our research question: Are people still aware of the risks associated with COVID-19? Although there is no evidence of foodborne transmission of COVID-19 (ICMSF International Commission on Microbiological Specifications for Foods, 2020), food handlers' personal hygiene and foodservice settings carry fatal COVID-19 transmission risks among individuals (WHO, 2020). In this regard, extant studies have not clarified how COVID-19 risk 
perceptions affect the relationships between local food consumption motivation, intention to consume local food, and intention to visit a particular destination. If the relationships among COVID-19 risk perceptions, local food consumption motivation, and intention to consume local food, as well as the relationship between local food consumption intention and destination visit intention, are examined accurately, DMOs can more accurately estimate tourists' risk perceptions. Against this background, the present study examines the moderating effects of COVID-19 risk perceptions on the relationships between local food consumption motivation, intention to consume local food, and intention to visit a destination.

\section{Literature Review}

\subsection{Motivations and intention to consume local food and intention to visit a destination}

Motivation is a phenomenon that drives individual behaviors (Sheldon et al., 2004). It includes factors that trigger, direct, and maintain said behaviors (Tsitkari et al., 2015). In the context of consumerism, motivation refers to the processes underlying purchase behaviors (Solomon et al., 2013). Various theories have been proposed to explain individuals' purchase behaviors (e.g., expectancy theory, hierarchy of needs theory, cognitive theory, instinct theory, and incentive theory). Tourism researchers have made various attempts to determine the motivation of tourists by adopting these theories (Crompton, 1979; Iso-Ahola, 1982). Across the board, motivation has been accepted as a series of factors that drive tourists to buy a particular product or service. In light of this established correlation, motivation is expected to be an important predictor of intention to consume local food.

Because the components of motivation vary according to the products in question, local food motivations exhibit specific components. Local food consumption motivations are considered a combination of both tourism and "dining out" motivations. However, local food differs from "dining out" as it involves a tourism-related concept. Dining out does not require a touristic activity. However, local food consumption is typically associated with culinary activities (Chang et al., 2020). As emphasized in the self-determination theory, there are both internal and external motivations: the former are based on satisfaction while the latter consist of external rewards (Iso-Ahola, 1982). According to the expectancy theory, consumers are motivated by the particular benefits of consumption (Overby and Lee, 2006). Therefore, the potential benefits that individuals may obtain from a touristic product can modify their motivations. Thus, motivations for local food are expected to be different from those related to "dining out." 
Various studies have averred that motivations drive tourists to consume local food (e.g., Mak et al., 2017). Motivations influencing tourists' intentions to consume local food in a destination have been described using such words as "exciting experience, escape from routine, health concern, learning knowledge, authentic experience, togetherness, prestige, sensory appeal and physical environment" (Kim et al., 2013).

Mak et al. (2013) identified five dimensions in food consumption motivation: contrast, extension, symbolism, obligation, and pleasure. Later on, Mak (2018) examined motivations underlying the food consumption of tourists and identified the motivational factors affecting tourists' food consumption in a foreign destination as authenticity and prestige, culture, novelty, variety, pleasure, assurance, familiarity, and health. Similarly, Su et al. (2020) identified tourists' food consumption motivations through push and pull factors, with the former including food taste, socialization, and cultural experience and the latter including core food-tourism appeals, traditional food appeals, and local destination.

Several scholars have used different terms to denote similar factors. Therefore, to determine the effect of each motivational factor on tourists' intention to consume local food, the following motivations are used: cultural experience, excitement, health concern, interpersonal relationship, novelty, and sensory appeal.

Learning about different cultures is one of the primary motivations for consumers to visit ethnic restaurants (Mak et al., 2011; Liu et al., 2017). Kim, Eves, and Scarles (2009) pointed out that local food serves as a cultural experience that allows visitors to understand the culture. For example, tourists may acquire information on table manners and different cooking methods. Individuals consuming local food interact with the cultural elements of the region, gaining lived knowledge through an authentic experience (Hjalager and Corigliano, 2000). Cultural experience has been identified as a major motivator of ethnic food consumption (Akyus, 2019; Allan, 2016; Kim et al., 2013). For this reason, cultural experience motivation may positively affect tourists' local food consumption intentions. Thus, the following hypotheses are proposed:

$H_{1 a} / H_{2 a}$ : Cultural experience motivation positively affects intention of local food consumption in Italy/Thailand.

Dining experiences could bring excitement to people's lives (Kim and Eves, 2012). Eating new local foods is one of the exciting experiences of travel (Ahmad et al., 2020; Okumus et al., 2021). Excitement is a key motivation for tourists to consume ethnic foods while traveling (Kim et al., 2013). Excitement includes "exciting experiences" and "getting out of the routine." Tourists' experiences of different foods can create the feeling of being away from their usual everyday environments back home (Kim et al., 2009). Therefore, it can be expected that 
excitement motivation will positively affect intention of local food consumption. Thus, the following hypotheses are proposed:

$H_{1 b} / H_{2 b}$ : Excitement motivation positively affects intention of local food consumption in Italy/Thailand.

Health concern is generally among the most determinant factors in the intention to consume food for all individuals (Sparks et al., 2003). While some tourists avoid eating certain local foods over perceived hygiene concerns (Torres and Skillicorn, 2004), others are motivated by health benefits to consume local food at destinations (Kim et al., 2009). Yuksel and Yuksel (2002) identified a cluster of tourists as "healthy-food seekers" who prefer restaurants offering healthy and nutritious food. According to Ayyub (2015), the desire for healthy food is one of the main reasons for the rising popularity of ethnic food. It can be expected that health concern will shape intention of local food consumption positively. Thus, the following hypotheses are proposed:

$H_{1 c} / H_{2 c}$ : Health Concern motivation positively affects intention of local food consumption in Italy/Thailand.

Socialization has been recognized as a major motivation for food consumption (Kim et al., 2013; Yuan, 2005). Tourists' consumption of local food while vacationing not only allows them to meet new people but also helps reinforce their social relations with the people they go on vacation with (family, relatives, friends, etc.) (Getz et al., 2014). In addition, food provides a good opportunity for social interaction among tourists, local people, chefs, and caterers ( $\mathrm{Su}$ et al., 2020). At this point, it can be expected that tourists' interpersonal relationship motivations will positively affect intention of local food consumption. Thus, the following hypotheses are proposed:

$H_{1 d} / H_{2 d}$ : Interpersonal relationship motivation positively affects intention of local food consumption in Italy/Thailand.

Another element in tourism motivations is novelty seeking (Dann, 1981). People constantly need change, and participating in tourism activities offers people the chance to meet this need. Local food can excite individuals by offering different tastes that they are not used to (Kim and Choe, 2019). Consuming exotic cuisine helps tourists satisfy their curiosity and experience novelty (Quan and Wang, 2004). In addition, by consuming local food, individuals go out of their ordinary environments and change their routines to accommodate such experiences (Kim et al., 2009). In this context, it can be expected that novelty motivation will positively affect intention of local food consumption. Thus, the following hypotheses are proposed: 
$H_{1 e} / H_{2 e}$ : Novelty motivation positively affects intention of local food consumption in Italy/Thailand.

The sensory experience is also a primary motivation to travel for food (Boniface, 2003). Local food provides tourists with a physical experience through sensory perceptions of taste, visual appearance, and smell (Kim et al., 2009). The sensory appeal of local cuisine is a driving force for tourists to eat local food (Suntikul et al., 2020). The sensory experience is a major factor that tourists consider in local food consumption (Kim \& Eves, 2012). Therefore, it can be expected that the sensory appeal motivation for local food will positively affect intention of local food consumption. Thus, the following hypotheses are proposed:

$H_{1 f} / H_{2 f}$ : Sensory appeal motivation positively affects intention of local food consumption in Italy/Thailand.

Intention to consume local food is one of the significant predictors of intention to visit a destination (Okumus et al., 2007). Local food consumption offers tourists an authentic experience and cultural experience. Furthermore, tourists' social value perceptions can increase by experiencing local food consumption (Fields, 2002). The advantages of local food consumption have the potential to increase tourists' intention to visit a destination. Thus, the following hypotheses are proposed:

$H_{3} / H_{4}$ : Intention of local food consumption positively affects the intention to visit two destinations-Italy/Thailand.

\subsection{Risk perception of COVID-19}

The tourism industry has been among the sectors most adversely affected by the COVID19 pandemic (Dedeoğlu and Boğan, 2021). The restriction measures have resulted in a sharp decline in international tourism. According to the World Tourism Organization, international tourism activities dropped by $74 \%$ worldwide, $71 \%$ in Europe, $84 \%$ in Asia, and $69 \%$ in North America (UNWTO, 2021). Economic difficulties emerged with the decline in touristic activities and many companies had difficulty preserving business continuity. Therefore, governments have announced various plans and programs to support the tourism sector (Dedeoğlu and Boğan, 2021). For example, the Italian government postponed financial loans, leasing contracts, and employee taxes for three months to support the liquidity of companies (ICOMIA The International Council of Marine Industry Associations, 2020). Although such national plans and programs may create confidence in the face of the pandemic, the infection risks are still a reality of daily life. Moreover, neglectful behaviors continue among individuals and tourists who are aware of the travel risks. Therefore, understanding tourists' COVID-19 travel risk 
perceptions is crucial. The question of how risk perceptions shape tourists' intentions is crucial for DMOs.

Cui et al. (2016) stated that tourists' risk perceptions are discussed generally through the dimensions of psychological risk, physical risk, time risk, financial risk, performance risk, health risk, and social risk. Tourists feel health risk perceptions "when the body would be injured due to illness, accident, security and other factors during the trip" (Cui et al., 2016, p. 649). The COVID-19 infection is associated with health risk. However, the risk perception of COVID-19 is different than other health risks because COVID-19 has caused a worldwide pandemic and the definitive treatment is not still available. This situation makes tourists' risk perceptions of COVID-19 a more important factor in determining their behaviors and attitudes (Dedeoğlu and Boğan, 2021).

All countries are facing major problems due to the COVID-19 pandemic. Most of them have had to implement restrictions to reduce the risk of infection, especially with the shortage of hospital resources (Oraby et al., 2021). The restrictions have kept COVID-19 cases under relative control for two years. However, due to partial relaxations and the emergence of different COVID-19 variants, countries have faced increasing a "second wave" or "third wave" of cases (Di Domenico et al., 2020). While it is clear that we are living in the age of the pandemic, our needs as social beings must still be met (Rozenkrantz et al., 2020). At this point, most countries have partially allowed active and passive tourism activities both due to social demands and out of a desire to preserve the economic cycle. Besides, through the use of different types of vaccines (i.e., BioNTech, Sinovac, Moderna, Sputnik V), people are trying to adapt to the so-called new normal (Contreras, 2021). One of the realities of this new normal is that tourists will go on vacations despite the risks of COVID-19 infection. The possible impact of individuals' risk perceptions on consumption patterns has yet to be fully understood. Individuals' behavioral intentions (i.e., local food consumption intention, visit intention) are easily affected by a paradoxical combination of desire (i.e., motivation) and fear (health risk). Therefore, the risk perceptions of COVID-19 are expected to impact the effect of (1) motivations of local food consumption on the intention to consume local food and (2) the intention to consume local food on the intention to visit a destination. Thus, the following hypotheses are proposed:

$H_{5 a} / H_{6 a}$ : Risk perception has a moderating effect on the relationship between cultural experience motivation and intention of local food consumption in Italy/Thailand.

$H_{5 b} / H_{6 b}$ : Risk perception has a moderating effect on the relationship between excitement motivation and intention of local food consumption in Italy/Thailand. 
$H_{5 c} / H_{6 c}$ : Risk perception has a moderating effect on the relationship between health concern motivation and intention of local food consumption in Italy/Thailand.

$H_{5 d} / H_{6 d}$ : Risk perception has a moderating effect on the relationship between interpersonal relationship motivation and intention of local food consumption in Italy/Thailand.

$H_{5 e} / H_{6 e}$ : Risk perception has a moderating effect on the relationship between novelty motivation and intention of local food consumption in Italy/Thailand.

$H_{5 f} / H_{6 f}$. Risk perception has a moderating effect on the relationship between sensory motivation and intention of local food consumption in Italy/Thailand.

$\mathrm{H}_{7} / \mathrm{H}_{8}$ : Risk perception has a moderating effect on the relationship between intention of local food consumption and intention to visit Italy/Thailand.

[Insert Figure 1 here]

\section{Methodology}

For the present research, we conducted two studies. In the first study, we examined how the motivation of potential Chinese tourists regarding the consumption of local Italian food influenced their intention to consume Italian food and visit Italy, and how the perceived risk associated with COVID-19 shaped the aforementioned relationships. Similarly, in the second study, we analyzed how the motivation of potential Chinese tourists regarding the consumption of local Thai food influenced their intention to consume Thai food and visit Thailand, and how the perceived risk associated with COVID-19 shaped the aforesaid relationships. In both studies, the same scale structures were applied. Only target destinations and local foods were adapted specifically for Italy and Thailand. Likewise, both of the studies implemented the same analysis processes, and the findings were compared.

\subsection{Instrument}

The survey was used as a data collection tool in this research. The survey consists of two parts. In the first part, measurement items associated with motivations to consume local food, intention for local food consumption, intention to visit the destination, and risk perception of COVID19 were included. The second part contains statements regarding the participants' demographic characteristics. The motivations of local food consumption are examined through the following dimensions: novelty, cultural experience, excitement, interpersonal relationship, sensory appeal, and health concern. Novelty is measured with three statements, cultural experience with five statements, excitement with five statements, interpersonal relationship 
with three statements, sensory appeal with three statements, and health concern with four statements. The scales for local food consumption motivation were adopted from Kim et al. (2013) and Mak (2018). Intention for local food consumption is measured with six statements based on Seo et al. (2013). Intention to visit the destination is measured with six statements by Tan and Wu (2016) and Reza Jalilvand et al. (2012). The risk perception of COVID-19 was measured with four statements created by the authors.

The survey was translated into Chinese since it was applied to potential Chinese tourists in the business and leisure sectors. A back-translation process was applied (Brislin, 1976). After this process, the clarity of the statements was validated by administering the pilot test to 32 people. After the pilot test, one statement from excitement, two statements from intention for local food consumption, and two statements from intention to visit destination were removed from the questionnaire.

\subsection{Sampling and data collection}

Two questionnaires were created online (one focusing on Italian food and the other on Thai food) via sojump.com, whereby a prize draw was embedded at the end offering a cash prize of CNY 20 or gifts of equivalent value. The links were shared within one of the author's alumni networks. Ten key alumni were contacted to assist with data collection due to the nature of their work (e.g., tour guides, travel KOLs on social media, managers of travel agencies, event planners, and restaurant owners) and their places of residence (Beijing, Shanghai, Guangzhou, Nanjing, Qingdao, and Dalian), which are located in the top outbound source markets in China according to a 2019 China Outbound Tourism Development Report. The 10 research assistants then shared the links to the questionnaires via their social networks such as WeChat (including groups, moments, and individual contacts) and Weibo with their friends, colleagues, customers, and followers who are potential or experienced culinary tourists. They were recommended to recruit participants of different demographic backgrounds, which were then compared with the outbound Chinese tourists' profile as described by the 2019 China Outbound Tourism Development Report. A mixture of snowball and purposive sampling was adopted to select respondents with enough appropriate information to contribute meaningfully to the survey. The data collection lasted from 20 May 2020 to 30 June 2020. During this period, restaurants in most cities in China were back in business and domestic travel was beginning to resume. In total, 721 questionnaires were collected. The data were then subjected to a screening process, whereby questionnaires with irrational repetitive answers and extremely short completion times were removed to ensure reliability, resulting in 541 usable questionnaires. 


\subsection{Data analysis}

Partial least squares structural equation modeling (PLS-SEM) is considered an appropriate method for studies with small sample sizes and with constructs that have not gained full recognition in the literature yet. The current study has an exploratory nature, being one of the first studies investigating risk perceptions of COVID-19 in the tourism context. It has been stated that PLS-SEM is more appropriate for exploratory researches (Hair, Hult, et al., 2017a). PLS-SEM is also a suitable method for analyzing data collected via ordinal scales, such as Likert's scales, and an effective and efficient method for "explanation and prediction" (Hair et al., 2017b). Therefore, PLS-SEM was deployed to test the proposed model in this study. PLSSEM was performed using SmartPLS 3.3.3 (Ringle et al., 2017). A bootstrap resampling technique considering 5000 sub-samples (Hair et al., 2017a) was used to determine the values of the t-test. The PLS-SEM path model consists of two elements: the measurement model and the structural model. The measurement model was checked before the structural model. Besides that, the two-stage approach suggested by Hair et al. (2017a) was chosen as it was aimed to disclose the significance of the moderating effect of risk perception concerning COVID-19.

Nonetheless, the data screening process was implemented before applying a PLS-SEM application as suggested by Hair et al. (2013). The same stages were followed in both studies. Accordingly, the missing values were checked. There was no missing value found in either of the data sets. Then, the Mahalanobis distance was examined to investigate outliers, and no outlier values were found in either data set. Lastly, the values of skewness and kurtosis were analyzed, and both data sets were reported to meet the normal distribution assumption (Curran et al., 1996).

\section{Findings}

\subsection{Study 1 (Italy)}

\subsubsection{Demographic findings}

In Table I, the demographic characteristics of the participants are summarized. Women constitute $59.5 \%$ of the participants. At the same time, $41.3 \%$ of the participants have an income of $\$ 428$ and below. The rate of married participants is $43.6 \%$. The ratio of participants between the ages of 21-40 is $52.3 \%$. Participants holding an undergraduate education degree represent $64 \%$ of the sample.

[Insert Table I here] 


\subsubsection{Testing of hypotheses}

Internal consistency, convergent validity, and discriminant validity were examined for the measurement model (Hair et al., 2017a). The measurement model results are summarized in Table II.

\section{[Insert Table II here]}

As seen in Table II, Cronbach's alpha values are between .84 and .95, and composite reliability values are between 90 and .96. Besides, AVE values are over .50. The outer loadings are between .74 and .96 . Accordingly, it can be stated that internal consistency and convergent validity are obtained. The discriminant validity was examined by taking into account the criteria of Fornell and Larcker (1981). As can be seen in Table III, according to the Fornell and Larcker method, discriminant validity was provided because the square root of the AVE values was lower than the correlations of the relevant variables. Also, Table III shows the correlations between the structures. As suggested in theory, the relationships between the structures are significant and positive. Therefore, nomological validity has been achieved (Hair et al., 2013).

\section{[Insert Table III here]}

Collinearity problem (VIF), path coefficients $(\beta)$, determination coefficient $\left(R^{2}\right)$, effect size $\left(f^{2}\right)$, and Stone-Geisser's $Q^{2}$ value were examined for the testing of the structural model (Hair et al., 2017a). These findings are summarized in Table IV. Since the VIF values are not above 5, collinearity problems were not detected. Second, path coefficients were examined. As seen in Table IV, the cultural experience, novelty, and sensory appeal aspects of motivation have a significant and positive effect on the intention for local food consumption. Accordingly, $H_{l a}, H_{l e}$, and $H_{l f}$ were supported. Also, the intention for local food consumption of potential tourists positively and significantly influenced their intention to visit the destination. Thus, $H_{3}$ is also supported. When the R2 value is examined, it is reported that $52.4 \%$ of potential tourists' intention for local food consumption is shaped by cultural experience, novelty, and sensory appeal motivations. In addition, the intention of potential tourists to visit Italy has an explanation rate of $18.2 \%$ by the antecedent factors.

When the $f^{2}$ values are examined, it is seen that the cultural experience $\left(f^{2}=.03\right)$ and sensory appeal $\left(f^{2}=.04\right)$ are effective at a small level, while novelty $\left(f^{2}=.15\right)$ appears to be moderately effective on the intention for local food consumption of potential tourists. StoneGeisser's $Q^{2}$ value was taken into consideration for the assessment of predictive relevance. For 
the examination of $Q^{2}$, the cross-validated redundancy value recommended by Hair et al. (2011) was utilized. The $Q^{2}$ value was obtained by using a blindfolding procedure. As the $Q^{2}$ value is larger than zero concerning the intention for local food consumption $\left(Q^{2}=.449\right)$ and for intention to visit destination $\left(Q^{2}=.135\right)$, its explanatory latent construct exhibits a predictive relevance.

\section{[Insert Table IV here]}

Findings concerning the moderating effect of COVID-19 risk perception are listed in Table V. As shown in Table V, COVID-19's perception of risk plays a role in decreasing the effect on intention of local food consumption of both cultural experience and novelty motivations. To be more precise, as the risk perceptions of COVID-19 among potential tourists increase, the effects of cultural experience and novelty motivations on the intention for local food consumption decrease.

$$
\begin{aligned}
& \text { [Insert Table V here] } \\
& \text { [Insert Figure } 2 \text { here] }
\end{aligned}
$$

\subsection{Study 2 (Thailand)}

\subsubsection{Demographic findings}

In Table VI, the demographic characteristics of the participants in Study 2 are summarized. Women constitute $52.7 \%$ of the participants. At the same time, $27.8 \%$ of participants had an income of $\$ 428$ or below. The married participants' percentage is $56.3 \%$. The percentage of participants between the ages of $21-40$ is $68.2 \%$. The percentage of participants holding an undergraduate education degree is $60.6 \%$.

\section{[Insert Table VI here]}

\subsubsection{Testing of hypotheses}

The steps followed for Study 1 were also applied for Study 2. Accordingly, first, the outer model was tested. As shown in Table VII, all outer loadings exceeded the minimum cutoff point of .40 (Hair et al., 2017a), meaning that internal consistency was achieved. In terms of convergent validity, all the composite reliability (CR) values were above the minimum cutoff 
point of 0.70 (Fornell and Larcker, 1981) while all of the average variance extracted (AVE) values met the minimum criteria of .50 (Fornell and Larcker, 1981).

[Insert Table VII here]

According to Fornell and Larcker (1981), the square root of the AVE of each construct should exceed the correlation shared between the construct and other constructs in the model to achieve discriminant validity. As seen in Table VIII, discriminant validity is provided. Also, Table VII shows the correlations between the structures. As suggested in theory, the relationships between the structures are significant and positive. Therefore nomological validity has been achieved (Hair et al., 2013).

[Insert Table VIII here]

In Table IX, the inner model results are summarized. Since the VIF values are not above 5 , the collinearity problem was not detected. Secondly, the path coefficients were examined.

As shown in Table IX, all factors of motivation excluding excitement and interpersonal relationship significantly affect the intention for local food consumption. Also, the intention for local food consumption affected the intention to visit destinations positively and significantly. Accordingly, $\mathrm{H}_{2 a}, \mathrm{H}_{2 c}, \mathrm{H}_{2 e}, \mathrm{H}_{2 f}$, and $\mathrm{H}_{4}$ were supported. When the R2 value is examined, it is reported that $62.9 \%$ of potential tourists' intention for local food consumption is shaped by cultural experience, health concern, novelty, and sensory appeal motivations. In addition, the intention of potential tourists to visit Thailand has an explanation rate of $23.2 \%$ by the a priori variables. According to the $f^{2}$ value (Cohen, 1988), cultural experience (.04), health concern (.03), and sensory appeal (.05) have a small effect while novelty has a medium-large effect (.28) on intention for local food consumption. Intention for local food consumption has a mediumlarge effect (.31) on intention to visit the destination. Stone-Geisser's $Q^{2}$ value has been taken into consideration for assessment of the predictive relevance of intention for local food consumption and intention to visit the destination. In the $Q^{2}$ examination, the cross-validated redundancy value recommended by Hair et al. (2011) was applied. The $Q^{2}$ value is obtained by using a blindfolding procedure. As the $Q^{2}$ values for the intention for local food consumption and intention to visit destination are larger than zero, the explanatory latent construct exhibits a predictive relevance (Henseler et al., 2009). 
Findings regarding the moderating role of risk perception of COVID-19 for Study 2 are summarized in Table X. As shown in Table X, the risk perception of COVID-19 decreases the effect of all motivational factors on the intention of local food consumption. To be more precise, as the risk perceptions of COVID-19 among potential tourists increase, the influencing power of their motivations on the intention for local food consumption decreases.

[Insert Table X here]

[Insert Figure 3 here]

\section{Conclusion and implications}

This study explored how the local food motivations of Chinese tourists shape their intention to visit a destination during the COVID-19 outbreak. In addition, while investigating these relationships, the attitudes toward two target destinations that represented proximity (Thailand) and distance (Italy) were examined. In this context, the current research took a tripartite approach. First, this study examined the impact of potential Chinese tourists' local food consumption motivation on their intention to consume local food. Second, the impact of tourists' intentions to consume local food on their desire to visit that destination was examined. Third, the effect of risk perception of COVID-19 on these relationships was investigated. In this context, it can be said that the motivations of cultural experience, novelty, and sensory appeal are determinative in the local food consumption intention of Chinese tourists regarding both Thai food and Italian food. In addition, in terms of local food in Thailand, potential tourists' risk perception of COVID-19 has further shaped the effect of motivations on local food consumption intentions.

\subsection{Theoretical implications}

The results of Study 1 revealed that motivational factors such as cultural experience, novelty, and sensory appeal are effective in potential Chinese tourists' intention to consume Italian food. This finding is similar to previous studies that revealed the importance of cultural experience, novelty, and sensory appeal in terms of local food consumption (e.g., Kim and Eves, 2012). In addition, this finding also shows the effect of COVID-19 risk perception in reducing the impact of potential tourists' cultural experience and novelty motivations on the intention to consume Italian food. This finding aligns with previous studies that emphasize the 
effects of individuals' risk perception on food consumption or food preference tendencies (i.e., Cui et al., 2016; Dedeoğlu and Boğan, 2021). Since risk perception refers to the probability of an individual being harmed by a particular situation (Trumbo et al., 2016), potential tourists could predict and move away from the possible negative consequences that COVID-19 may cause.

Unique and memorial culinary experiences (i.e., cultural experience and novelty) are associated with limited interaction. Therefore, it is expected that tourists should have little or no knowledge or experience about local food in a given destination. However, when unique culinary experiences interact with COVID-19 risk perceptions, the local food consumption intention of tourists will be affected adversely. As a result, even though cultural experiences and novelty motivations may increase the local food consumption tendency, COVID-19 risk perceptions may decrease the effect of these motivations.

The findings of Study 2 revealed that motivational factors such as cultural experience, health concern, novelty, and sensory appeal influence tourists' intention to consume Thai food. The findings are similar to Study 1 so it can be stated that local food motivations may still influence the intention of local food consumption during COVID-19. This finding is similar to previous studies that reveal the effectiveness of local food motivations (e.g., Chang et al., 2020). Besides, the moderating role of COVID-19 risk perception is more prominent in Study 2. That means COVID-19 risk perception reduces potential tourists' motivation toward all local food and blocks the intention of local food consumption distinctively. Considering the findings of both studies, COVID-19 risk perception is more determinant in the context of Thai food motivations. This may be due to the cultural similarity or location of Thailand, which is closer to China than Italy. If the target culture and destination are closer to the place where potential tourists live, more information can be obtained. Given this, potential tourists will be able to obtain some information about the possible risks of a destination posed by COVID-19, and such risk perceptions will influence tourists' attitudes significantly.

Moreover, the intention to consume local food will positively influence the intention to visit both destinations, and COVID-19 risk perceptions do not moderate this relationship. Accordingly, as the intention to consume local food increases, the risk perceptions of individuals regarding COVID-19 will not prevent their intention to visit the destination. This reveals the importance of activating individuals' intention to consume local food. If the intention of potential tourists to consume local food can be increased sufficiently, the negative impact of the risk they will perceive regarding COVID-19 can be eliminated. Of course, at this point, the intention to consume local food may not be expected to be a sufficient reason to prefer 
a destination alone. To put it more clearly, potential tourists intend to consume local food as a result of the benefits of consuming local food and their intention to visit that destination. In this case, the risk perceptions created by COVID-19 can be eliminated.

\subsection{Practical implications}

Among the most important findings of this study is that risk perceptions related to COVID-19 reduce the relationship between local food consumption motivations and local food consumption intentions. In this context, to reduce the negative effects of COVID-19 risk perceptions, DMOs should focus primarily on the culinary motivation of potential tourists. Despite the COVID-19 pandemic, cultural experience, novelty, and sensory appeal motivations can increase the intention of local food consumption. Therefore, DMOs should emphasize the cultural experience, novelty, and sensory appeal factors in their promotion efforts. For example, DMOs should promote local foods with cultural elements. Such introductions should focus on elements that will appeal to novelty and sensory appeal motivations. In addition to traditional media tools, social media tools can be used at the point of promotion. DMOs could, for example, develop promotions that encourage different tourists to share their local food consumption experiences. According to the amount of content created regarding local food consumption experiences, discount coupons could be provided to be redeemed at different businesses within the destination.

However, COVID-19 risk perceptions should be considered by DMOs and potential tourists should be convinced that destinations can control the infection risks effectively. Currently, many destinations operate with a relatively high degree of certainty, planning their annual process, setting their budgets, and studying traveler behavior to frame marketing plans clearly (BCG-Google, 2021). Potential tourists should reach the relevant information about the destinations' COVID-19 management plan and actions on reducing the risk of virus transmission and infection. For example, Turkey has implemented safe tourism certification programs as well as tourist protection and support insurance and COVID-19 accommodation support insurance programs (TGA Türkiye Tourism Promotion and Development Agency, 2021). Similarly, Israel accepts fully vaccinated foreign tourists (Ledsom, 2021). Countries may request cards from individuals who will travel, showing their status and whether they have been vaccinated against COVID-19. To be even more comprehensive, an online system can be developed under the coordination of the World Health Organization and United Nations World Tourism Organization, and past and current information about the COVID-19 situation of each individual who will travel can be collected. Because the risk of transmission of all forms of 
COVID-19 is under control, risk perceptions are generally reduced. Such measures may reduce risk perceptions and increase the motivations of potential tourists toward visiting a new destination and trying local foods at that destination. Overall, this study shows that the negative effects pertaining to the risk perceptions of COVID-19 vary across destinations. The risk perceptions of COVID-19 may fluctuate from country to country and the intention to consume local food may be affected by such risk perceptions. Therefore, motivations such as cultural experience, novelty, health concern, and sensory appeal should be considered influential factors that shape potential tourists' attitudes toward future tourism destinations.

\section{Disclosure statement}

No potential conflict of interest was reported by the authors.

\section{References}

Ahmad, M.S., Jamil, A., Latif, K.F., Ramayah, T., Ai Leen, J.Y., Memon, M. and Ullah, R. (2020), "Using food choice motives to model Pakistani ethnic food purchase intention among tourists", British Food Journal, Vol. 122 No. 6, pp. 1731-1753.

Allan, M. (2016), "Exploring the relationship between local food consumption and intentional loyalty”, Revista de turism-studii si cercetari in turism, Vol. 21, pp. 33-38.

Back, R. M., Okumus, B., \& Tasci, A. D. (2020). Culinary fans vs culinary critics: characteristics and behavior. International Hospitality Review. 34(1), 41-60.

Boniface, P. (2003). Tasting tourism: Traveling for food and drink. Burlington, VT: Ashgate.

Brislin, R.W. (1976), “Comparative research methodology: Cross-cultural studies”, International Journal of Psychology, Vol. 11 No. 3, pp. 215-229.

BusinessToday. (2020), “COVID-19 will be around for next 10 years, says BioNTech CEO Ugur Sahin”, available at: https://www.Businesstoday.in/Current/EconomyPolitics/Covid-19-Will-Be-around-for-next-10-Years-Says-Biontech-Ceo-UgurSahin/Story/425854.Html (accessed 15 January 2021)

BCG-Google (2021). Actions for Destination Marketers to Navigate in a COVID-19 World. https://www.thinkwithgoogle.com/_qs/documents/10309/Actions_for_Destination_Mark eters_.pdf (accessed 15 April 2021)

Chang, J., Morrison, A.M., Lin, S.H.H. and Ho, C.Y. (2020), "How do food consumption motivations and emotions affect the experiential values and well-being of foodies?", British Food Journal, Vol. 123 No. 2, pp. 627-648.

Contreras, G.S. (2021), "In Search of the Hopeful COVID-19 Vaccine. Who will Win the 
Race to a New Normal?”, Journal of Health Management, 0972063420983092.

Crompton, J. (1979), “Motivation for pleasure vacation”, Annals of Tourism Research, Vol. 6 No. 4, pp. 408-424.

Cui, F., Liu, Y., Chang, Y., Duan, J. and Li, J. (2016), “An overview of tourism risk perception”, Natural Hazards, Vol. 82, No. 1, pp. 643-658.

Curran, P.J., West, S.G. and Finch, J.F. (1996), "The robustness of test statistics to nonnormality and specification error in confirmatory factor analysis", Psychological methods, Vol. 1 No. 1, pp. 16-29.

Dann, G. M. (1981), “Tourist motivation an appraisal”, Annals of tourism research, Vol. 8 No. 2, pp. 187-219.

Dartford, K. (2021), “We’ve had enough”:In France, Spain and Denmark, anti-lockdown protests continue", available at: https://www.Euronews.Com/2021/01/31/We-ve-HadEnough-in-France-Spain-and-Denmark-Anti-Lockdown-Protests-Continue (accessed 15 January 2021)

Dedeoğlu, B.B. and Boğan, E. (2021), “The motivations of visiting upscale restaurants during the COVID-19 pandemic: The role of risk perception and trust in government", International Journal of Hospitality Management, Vol.95, 102905.

Dedeoğlu, B.B., van Niekerk, M., Küçükergin, K.G., De Martino, M. and Okumuş, F. (2020), "Effect of social media sharing on destination brand awareness and destination quality", Journal of Vacation Marketing, Vol. 26 No. 1,pp. 33-56. available at:https://doi.org/10.1177/1356766719858644.

Dedeoğlu, B.B., Van Niekerk, M., Weinland, J. and Celuch, K. (2019), "Re-conceptualizing customer-based destination brand equity", Journal of Destination Marketing and Management, Vol. 11, pp. 211-230.

Di Domenico, L., Pullano, G., Sabbatini, C.E., Boëlle, P.Y. and Colizza, V. (2020), "Impact of lockdown on COVID-19 epidemic in Île-de-France and possible exit strategies", BMC Medicine, Vol. 18 No. 1, pp. 1-13.

Fields, K. (2002), "Demand for the Gastronomy Tourism Product: Motivational Factors”, in Hjalager, M. and Richards, G. (Eds.), Tourism and Gastronomy, Routledge, London, pp. $37-50$.

Fornell, C. and Larcker, D.F. (1981), "Evaluating Structural Equation Models with Unobservable Variables and Measurement Error", Journal of Marketing Research, Vol. 18 No. 1, pp. 39-50.

Getz, D., Robinson, R., Andersson, T., \& Vujicic, S. (2014). Foodies and food tourism. 
Oxford: Goodfellow Publishers Limited.

Gurbaskan Akyuz, B. (2019), "Factors that influence local food consumption motivation and its effects on travel intentions", Anatolia, Vol. 30 No. 3, pp. 358-367.

Hair, J.F., Babin, W.C., Babin, B.J., Anderson, R.E. and Tatham, R.L. (2013), Multivariate Data Analysis: Pearson New International Edition (Seventh Ed.), Pearson Education, Harlow, UK.

Hair, J.F., Hult, G.T.M., Ringle, C. and Sarstedt, M. (2017a), A Primer on Partial Least Squares Structural Equation Modeling (PLS-SEM) (Second Ed.), Second., Sage Publications, Thousand Oaks.

Hair, J.F., Matthews, L.M., Matthews, R.L. and Sarstedt, M. (2017b), "PLS-SEM or CBSEM: Updated guidelines on which method to use", International Journal of Multivariate Data Analysis, Vol. 1 No. 2, pp. 107-123.

Hair, J.F., Ringle, C.M. and Sarstedt, M. (2011), "PLS-SEM: Indeed a Silver Bullet”, Journal of Marketing Theory and Practice, Vol. 19 No. 2, pp. 139-152.

Hjalager, A.M. and Corigliano, M.A. (2000), "Food for tourists—-determinants of an image", International journal of tourism research, Vol. 2 No. 4, pp. 281-293.

ICMSF International Commission on Microbiological Specifications for Foods. (2020), "ICMSF opinion on SARS-CoV-2 and its relationship to food safety", available at: Https://Www.Icmsf.Org/Wp-Content/Uploads/2020/09/ICMSF2020-LetterheadCOVID-19-Opinion-Final-03-Sept-2020.BF_.Pdf (accessed 15 January 2021)

ICOMIA The International Council of Marine Industry Associations. (2020), "Italy Government support of industry during COVID-19”, available at: https://www.Icomia.Org/Content/Italy-Government-Support-Industry-during-Covid-19-0 (accessed 15 January 2021)

Iso-Ahola, S.E. (1982), “Toward a social psychological theory of tourism motivation: A rejoinder", Annals of Tourism Research, Vol. 9 No. 2, pp. 256-262.

Kim, S.S. and Choe, J.Y.J. (2019), “Testing an attribute-benefit-value-intention (ABVI) model of local food consumption as perceived by foreign tourists", International Journal of Contemporary Hospitality Management, Vol. 31 No. 1, 123-140.

Kim, Y.G. and Eves, A. (2012), "Construction and validation of a scale to measure tourist motivation to consume local food", Tourism Management, Pergamon, Vol. 33 No. 6, pp. $1458-1467$.

Kim, Y.G., Eves, A. and Scarles, C. (2009) "Building a model of local food consumption on trips and holidays: A grounded theory approach", International Journal of Hospitality 
Management, Vol. 28 No.3, pp. 423-431.

Kim, Y.G., Eves, A. and Scarles, C. (2013), "Empirical verification of a conceptual model of local food consumption at a tourist destination", International Journal of Hospitality Management, Vol. 33 No. 1, pp. 484-489.

Ledsom, A. (2021), "Israel to open international travel to vaccinated tourists in may", available at: https://www.Forbes.Com/Sites/Alexledsom/2021/04/13/Israel-to-OpenInternational-Travel-to-Vaccinated-Tourists-from-23-May/?Sh=2287c7c8344c, (accessed 13 April 2021)

Lee, T.H. (2020), "Creating the New Normal: The Clinician Response to COVID-19”, NEJM Catalyst Innovations in Care Delivery, Vol. 1 No.2, available at:https://doi.org/10.1056/CAT.20.0076.

Liu, H., Li, H., DiPietro, R.B. and Levitt, J.A. (2018), "The role of authenticity in mainstream ethnic restaurants: Evidence from an independent full-service Italian restaurant", International Journal of Contemporary Hospitality Management, Vol. 30 No. 2, pp. 1035-1053.

Mak, A.H.N. (2018), "Motivations Underlying Tourist Food Consumption", in Pforr, C. and Phau, I. (Eds.), Food, Wine and China: A Tourism Perspective, Routledge, Abingdon, pp. 72-95.

Mak, A.H.N., Lumbers, M., Eves, A. and Chang, R.C.Y. (2013), "Factors influencing tourist food consumption”, International Journal of Hospitality Management, Vol. 31 No. 3, pp. 928-936.

Mak, A.H.N., Lumbers, M., Eves, A. and Chang, R.C.Y. (2013), “An application of the repertory grid method and generalised Procrustes analysis to investigate the motivational factors of tourist food consumption", International Journal of Hospitality Management, Vol. 35, pp. 327-338.

Mak, A.H.N., Lumbers, M., Eves, A. and Chang, R.C.Y. (2017), “The effects of food-related personality traits on tourist food consumption motivations", Asia Pacific Journal of Tourism Research, Vol. 22 No. 1, pp. 1-20.

Mariani, M., Bresciani, S. and Dagnino, G.B. (2021), "The competitive productivity (CP) of tourism destinations: an integrative conceptual framework and a reflection on big data and analytics", International Journal of Contemporary Hospitality Management, Vol. 33 No. 9, pp. 2970-3002.

Mariani, M., Buhalis, D., Longhi, C. and Vitouladiti, O. (2014), "Managing change in tourism destinations: key issues and current trends", Journal of Destination Marketing and 
Management, Vol. 2 No. 4, pp. 269-272.

Muhammad, S., Long, X. and Salman, M. (2020), “COVID-19 pandemic and environmental pollution: A blessing in disguise?", Science of the Total Environment, Vol. 728, p. 138820.

Okumus, B. and Cetin, G. (2018), “Marketing Istanbul as a culinary destination”, Journal of Destination Marketing and Management, Vol. 9, pp. 340-346.

Okumus, B., Fangfang, S. and Dedeoğlu Balıkçıoglu, S. (2021), "What is the Role of Demographics in Tourists' Attitudes Towards Foods?”, Journal of Gastronomy and Tourism, Vol. 5 No. 4., pp. 207-220.

Okumus, B., Okumus, F. and McKercher, B. (2007), “Incorporating local and international cuisines in the marketing of tourism destinations: The cases of Hong Kong and Turkey", Tourism Management, Vol. 28 No. 1, pp. 253-261.

Oraby, T., Tyshenko, M.G., Maldonado, J.C., Vatcheva, K., Elsaadany, S., Alali, W.Q., Longenecker, J.C. and Mustafa Al-Zoughool. (2021), "Modeling the effect of lockdown timing as a COVID-19 control measure in countries with differing social contacts", Scientific Reports, Vol. 11 No. 1, pp. 1-13.

Overby, J.W. and Lee, E.J. (2006), “The effects of utilitarian and hedonic online shopping value on consumer preference and intentions", Journal of Business Research, Vol. 59 No. 10-11, pp. 1160-1166.

Park, K.S., Reisinger, Y., \& Kang, H.J. (2008). "Visitors' motivation for attending the South Beach wine and food festival, Miami Beach. Florida." Journal of Travel \& Tourism Marketing, Vol. 25 No. 2, pp. 161-181.

Quan, S. and Wang, N. (2004), "Toward a structural model of the tourist experience: an illustration from food experiences in tourism", Tourism Management, Vol. 25 No. 3, pp. 297-305.

Reza Jalilvand, M., Samiei, N., Dini, B. and Yaghoubi Manzari, P. (2012), "Examining the structural relationships of electronic word of mouth, destination image, tourist attitude toward destination and travel intention: An integrated approach", Journal of Destination Marketing and Management, Vol. 1 No. 1-2, pp. 134-143.

Richards, G. (2021). Evolving research perspectives on food and gastronomic experiences in tourism. International Journal of Contemporary Hospitality Management. Vol. 33 No. 3, pp. 1037-1058.

Ringle, C.M., Wende, S. and Becker, J.M. (2017), "SmartPLS 3”, SmartPLS GmbH, Boenningstedt. 
Rozenkrantz, L., Bernstein, M.H. and Hemond, C.C. (2020), “A paradox of social distancing for SARS-CoV-2: loneliness and heightened immunological risk", Molecular Psychiatry, Vol.25 No.12, pp.3442-3444.

Seo, S., Kim, O.Y., Oh, S. and Yun, N. (2013), "Influence of informational and experiential familiarity on image of local foods", International Journal of Hospitality Management, Vol. 34 No. 1, pp. 295-308.

Sheldon, K.M., Ryan, R.M., Deci, E.L. and Kasser, T. (2004), “The independent effects of goal contents and motives on well-being: it's both what you pursue and why you pursue it.”, Personality \& Social Psychology Bulletin, Vol. 30 No. 4, pp. 475-86.

Soltani, M., Nejad, N. S., Azad, F. T., Taheri, B., \& Gannon, M. J. (2020). Food consumption experiences: a framework for understanding food tourists' behavioral intentions. International Journal of Contemporary Hospitality Management. Vol. 33 No. 1, pp. 75-100.

Solomon, M.R., Bamossy, G.J., Askegaard, S.T. and Hoog, M.K. (2013), Consumer Behaviour: A European Perspective, Fifth., Pearson Education, Edinburgh Gate, Harlow. Su, D.N., Johnson, L.W. and O'Mahony, B. (2020), “Analysis of push and pull factors in food travel motivation", Current Issues in Tourism, Vol. 23 No. 5, pp. 572-586.

Su, Z., Wen, J., McDonnell, D., Goh, E., Li, X., Šegalo, S., Ahmad, J., Cheshmehzangig, A. and Xiang, Y. (2021), "Vaccines are not yet a silver bullet: The imperative of continued communication about the importance of COVID-19 safety measures", Brain, Behavior, \& Immunity - Health, Elsevier BV, Vol. 12, p. 100204.

Suntikul, W., Pratt, S. and Chong, Y.W.J. (2020), "Factors that influence Chinese outbound tourists' intention to consume local food", Journal of China Tourism Research, Vol. 16 No. 2, pp. 230-247.

Tan, W.K. and Wu, C.E. (2016), “An investigation of the relationships among destination familiarity, destination image and future visit intention", Journal of Destination Marketing and Management, Vol. 5 No. 3, pp. 214-226.

TGA Türkiye Tourism Promotion and Development Agency. (2021), “Turkey’s begins tourism staff vaccination programme", available at: https://www.traveldailymedia.com/turkeys-begins-tourism-staff-vaccination-programme/ (accessed 15 April 2021)

Trumbo, C.W., Peek, L., Meyer, M.A., Marlatt, H.L., Gruntfest, E., McNoldy, B.D. and Schubert, W.H. (2016), “A Cognitive-Affective Scale for Hurricane Risk Perception”, Risk Analysis, Vol. 36 No. 12, pp. 2233-2246. 
Tsitkari, E., Vernadakis, N., Foridou, A. and Bebetsos, E. (2015), “Assessing Adolescent Sport Participation Motives: Psychometric Evaluation of BRSQ”, Motricidade, Vol. 11 No. 1, pp. 64-77.

UNWTO. (2021), “International tourism and COVID-19”, available at: https://www.Unwto.Org/International-Tourism-and-Covid-19 (accessed 15 January 2021)

Wang, Y., Hong, A., Li, X. and Gao, J. (2020), "Marketing innovations during a global crisis: A study of China firms' response to COVID-19”, Journal of Business Research, Vol. 116, pp. 214-220.

WHO. (2020), “Food Safety”, available at: https://www.who.int/news-room/factsheets/detail/food-safety (accessed 15 January 2021)

Yuan, J. J., Cai, L. A., Morrison, A. M., \& Linton, S. (2005). “An analysis of wine festival attendees' motivations: A synergy of wine, travel and special events?" Journal of Vacation Marketing, Vol. 11 No.1, pp. 41-58. 